\title{
Contribuição à Zooarqueologia do Sambaqui do Moa: novos vestígios ictiológicos
}

\author{
Sue Anne Regina Ferreira da Costa* \\ Zoneibe Augusto Silva Luz* \\ Maura Imazio da Silveira"t \\ Heloisa Maria Moraes-Santos ${ }^{*+*}$
}

COSTA, S.A.R.F.; LUZ, Z.A.S.; SILVEIRA, M.I.; SANTOS, H.M.M. Contribuição à

Zooarqueologia do Sambaqui do Moa: novos vestígios ictiológicos. R. Museu Arq.

Etn., São Paulo, n. 22: 51-65, 2012.

Resumo: Este trabalho apresenta a descrição e uma breve discussão sobre os vestígios icitológicos recuperados a partir de escavações realizadas no Sambaqui do Moa, localizado em Saquarema/RJ. Eles são 39 otólitos, pertencentes aos taxa: Cynoscion sp., Micropogonias furnieri, Pogonias cromis e Genidens genidens, e 9 dentes de tubarões dos gêneros Carcharhinus, Galeocerdo, Sphyrna, Carcharias e Isurus, inéditos até então para o sítio. A partir desses registros, foi possível verificar informações referentes ao paleoambiente e à utilização desses peixes para a cultura dos povos sambaquieiros.

Palavras-chaves: Zooarqueologia, Sambaqui do Moa, Peixes.

\section{Introdução}

$\mathrm{N}$

o Brasil, os sambaquis ocorrem em quase todo o litoral e em algumas

(*) Faculdade de Artes e Museologia, Universidade Federal do Pará. Rua Augusto Corrêa, 01 - Guamá. CEP 66075-110. Belém, Pará, Brasil. <suecosta@ufpa.br>

${ }^{(* *}$ Coordenação de Ciências da Terra e Ecologia, Museu Paraense Emílio Goeldi. Avenida Perimetral da Ciência no 1901, Terra Firme, CEP 66077-530, Belém, Pará, Brasil. <zoneibe. luz@gmail.com>

$\left.{ }^{* * *}\right)$ Coordenação de Ciências Humanas, Museu Paraense Emílio Goeldi. Avenida Perimetral da Ciência no 1901, Terra Firme, CEP 66077-530, Belém, Pará, Brasil. <maura.imazio@gmail.com>

${ }^{* * * *}$ ) Coordenação de Ciências da Terra e Ecologia, Museu Paraense Emílio Goeldi. Avenida Perimetral da Ciência n ${ }^{\circ}$ 1901, Terra Firme, CEP 66077-530, Belém, Pará, Brasil. <hmoraes@museu-goeldi.br> áreas fluviais, com registros desde o Pará até o Maranhão, e da Bahia até o Rio Grande do Sul, concentrados na região Sul-Sudeste (SILVEIRA, 2001; BANDEIRA, 2007). Eles são caracterizados pelo amontoado de conchas, fato anteriormente interpretado como representação de estruturas de acúmulos de restos alimentares, e construídos por bandos nômades, coletores de moluscos, com alta mobilidade territorial e baixa densidade demográfica (GUIMARÃES, 2003; SCHEEL-YBERT et al., 2009). Atualmente, no entanto, são considerados como estruturas intencionalmente estabelecidas, plenas de significação simbólica aos seus construtores, e os peixes como sua fonte alimentar principal, enquanto que as conchas seriam, provavelmente, a matéria-prima para a edificação dos montes (SCHEEL-YBERT, 2003, 2009, DeBLASIS et al., 2007). 
O Sambaqui do Moa, com aproximadamente $2.800 \mathrm{~m}^{2}$ de área (KNEIP, 1994), está localizado em Itaúna - Saquarema/RJ a 22055'44" $\mathrm{S}$ e $042^{\circ} 29^{\prime} 07^{\prime \prime}$ W, assentado sobre substrato arenoso, cordão de duna. Situa-se entre a lagoa de Saquarema e o mar, apresentando forma oval e o aspecto de uma pequena colina com aproximadamente $2 \mathrm{~m}$ de altura em relação ao rio Lêgo, que corre a NE do sambaqui. Ao escolherem este local para moradia, próximo à margem leste da lagoa, com acesso a qualquer ponto do recôncavo e protegidos dos fortes ventos oceânicos, os habitantes do sambaqui do Moa beneficiaram-se com a riqueza natural existente nos diversos ecossistemas encontrados nesta região (KNEIP et al., 1997).

O sambaqui apresenta-se muito perturbado por estar em área urbana, com ruas e construções edificadas. Contudo, existem alguns poucos terrenos com partes preservadas que ainda permitem pesquisas. Em 1988, Lina Kneip, realizou pesquisas neste sítio, em uma pequena área de $49 \mathrm{~m}^{2}$. Em aproximadamente $80 \mathrm{~cm}$ espessura foram evidenciadas duas camadas ocupacionais datadas por C14. A camada I corresponde ao período de $3.610 \pm 190$ A.P. e a camada II $3.960 \pm 200$ A. P. (KNEIP et al., 1988).

Em 1998 foi escavada por Silveira (2001) uma área de aproximadamente $120 \mathrm{~m}^{2}$, situada em um terreno localizado na Rua Abelardo Barbosa, 18, esquina com Herculano Gonçalves. Bairro: Itaúna, Saquarema/RJ. A partir das escavações por decapagem em níveis naturais (KNEIP et al., 1991 apud LEROI-GOURHAN \& BREZZILION, 1972), finalizada em $90 \mathrm{~cm}$ de profundidade quando se depara com a areia do cordão de duna e ausência de vestígios arqueológicos, foram reconhecidas três camadas, sucintamente caracterizadas por:

- Camada 1: espessura variando entre 10 e $25 \mathrm{~cm}$, composta por moluscos e solo sendo subdividida em $1 \mathrm{~A}$ e $1 \mathrm{~B}$;

- Camada 2: espessura em torno de 5 a $20 \mathrm{~cm}$, composta por uma grande quantidade de moluscos e ossos de peixes, apresentando-se de forma descontínua, e presente mais na parte "central" da área escavada; - Camada 3: espessura variável em torno de 30 a $50 \mathrm{~cm}$, composta por mais "solo" (areia) e menos moluscos, também foi subdividida em 3A e 3B.

A sequência estratigráfica indica que a camada 3 é a mais antiga, relacionada ao início da ocupação do sítio, ou seja, está associada ao período em que os habitantes do Sambaqui do Moa chegaram ao local por volta $3960 \pm 200$ AP. Na camada 2 observa-se a intensificação da exploração de moluscos e da pesca, sendo observados ossos de fauna bem maiores e uma grande quantidade de moluscos em relação às outras duas camadas ( 1 e 3). A camada 1 está relacionada à ocupação mais recente, ou seja, correspondem aos últimos níveis de ocupação deste sítio por volta de $3610 \pm 190$ AP (SILVEIRA, 2001).

Segundo Francisco (1999), que estudou a geologia dos sambaquis de Saquarema, a primeira ocupação do Moa, datada em $3960 \pm 200$ $\mathrm{AP}$, durou até o início da rápida transgressão ocorrida, possivelmente, entre 3.800-3.600 anos AP. Quando o nível do mar baixou, por volta de 3.600-2.800 anos AP, ocorre uma nova ocupação, datada em $3.600 \pm 190$ anos AP. Um novo período de elevação do nível do mar, entre 2.8002.500 anos AP obrigou ao abandono da área.

Durante as pesquisas foram evidenciados sepultamentos, fogueiras, pisos e buracos de esteio e estaca. Entre os vestígios coletados durante as pesquisas podem-se destacar ossos humanos e de animais, carapaças de moluscos, carvões e sementes, corantes, materiais líticos e na camada superficial alguns poucos fragmentos de cerâmica simples e utilitária (KNEIP, 1994; SILVEIRA, 2001). O material lítico é constituído por raspadores, furadores, pontas de flecha, lascas, lâminas de machados polidos, almofarizes, seixos com marcas de uso, quebra-coquinhos, percutores, corantes, fragmentos de rochas e resíduos de lascamento. O material de origem orgânica, depois de consumido, foi utilizado também na confecção de instrumentos e adornos, por exemplo, raspadores de conchas de Lucina pectinata; espátulas em valva de Ostrea 
sp.; anzol feito do lábio externo de Megalobulimus sp.; partes ósseas utilizadas como agulhas, espátulas, raspadores, furadores, pontas de diversos tamanhos (simples, duplas), osso seccionado - representando etapa no processo de manufatura de artefatos -, vértebras de tubarão perfuradas no centro, provavelmente utilizadas como adorno (SILVEIRA, 2001).

Os vestígios de animais em sítios arqueológicos, chamados zooarqueológicos, são importantes não só para estudos relacionados à organização social das populações, assim como seus sistemas, estrutura e funcionamento (GUIMARÃES, 2003), como também para reconstruções paleoambientais e paleoecológicas (p.e. GONZALEZ \& AMENOMORI, 2003, EVANS, 1972, MACHADO et al., 2011), a partir das identificações taxonômicas e o estado de preservação dos mesmos (CASTILHO \& SIMÕES-LOPES, 2001, LAM et al., 2003).

Em sambaquis, com exceção dos moluscos, se compararmos a ocorrência de vestígios de fauna, os restos de peixes (principalmente dentes e otólitos) são em geral abundantes, incluindo ainda os microvestígios, como os apresentados por Machado et al. (2011), em que diferentes tipos de dentes microscópicos de peixes foram achados nas diferentes camadas do Sambaqui do Moa. A análise deste tipo de material é importante, uma vez que indica/evidencia preferências alimentares da população em diferentes épocas, e também auxiliam nas reconstruções paleoambientais e paleoecológicas.

Os acúmulos de vestígios de peixes ao longo destes estratos possibilitam explorar aspectos não só ambientais como também culturais desses povos ao longo da sua história, mesmo considerando que o número de vestígios encontrados nos diferentes recortes espaço-temporais da evolução desses povos, aqui representados pelos estratos, sempre será menor do que a ocorrência real dos mesmos no ambiente (GONZALEZ, 2005).

\section{Material e metódos}

O material apresentado neste artigo foi coletado no Sambaqui do Moa por Silveira
(2001), durante as escavações em uma área de $120 \mathrm{~m}^{2}$, onde os vestígios macroscópicos foram coletados. Os dentes de tubarões (peixes cartilaginosos) e os otólitos (em peixes ósseos) aqui analisados foram coletados nas escavações (in situ ou por peneiramento) ou em laboratório, durante a triagem do material coletado. Assim, a análise desta amostra visa a complementar os dados levantados anteriormente por Silveira (2001) em sua tese de doutorado.

Analisou-se um total 48 espécimes de peixes, sendo 9 dentes isolados de tubarões e 39 otólitos. Todo material encontra-se depositado na Coleção Zooarqueológica do Museu Paraense Emílio Goeldi (MPEG), temporariamente instalada nas dependências do Acervo de Paleontologia do MPEG.

A identificação dos dentes de tubarões foi realizada com base em estudos comparativos com espécimes atuais, além de referências tais como, a Chave de Classificação para dentes de tubarões do Neógeno: Compagno (1984), Cappetta (2012) e Purdy (2006). Para a identificação utilizaram-se as diferentes topografias apresentadas nos dentes, tais como: formato geral da coroa, curvatura, presença ou ausência de serrilhações na borda e diversas variações como, por exemplo, a profundidade de um entalhe na parte basal da coroa (PURDY, 2006). Essas principais topografias utilizadas estão sumarizadas na figura abaixo (Fig. 1).

Para estes, a identificação taxonômica ocorreu com base em comparação morfológica com material recente disponibilizado pelo Dr. Orangel Aguilera (Pesquisador Visitante-MPEG), além de referências, por exemplo, Higuchi (1982) e Aguilera \& Aguilera (2003; 2004). A identificação foi realizada considerando-se o tipo diagnóstico para família, dentre os três tipos existentes de otólitos: sagitta, lapillus e asteriscus (HIGUCHI, 1982), Desse modo, os membros da família Scianidade foram determinados a partir da morfologia do sagitta, o otólito diagnóstico para a taxonomia (AGUILERA, 2003, 2004, 2010), mais precisamente com base na forma do óstio e da cauda (Figura 2B). Já para os Ariidae, o lapillus é o princi- 

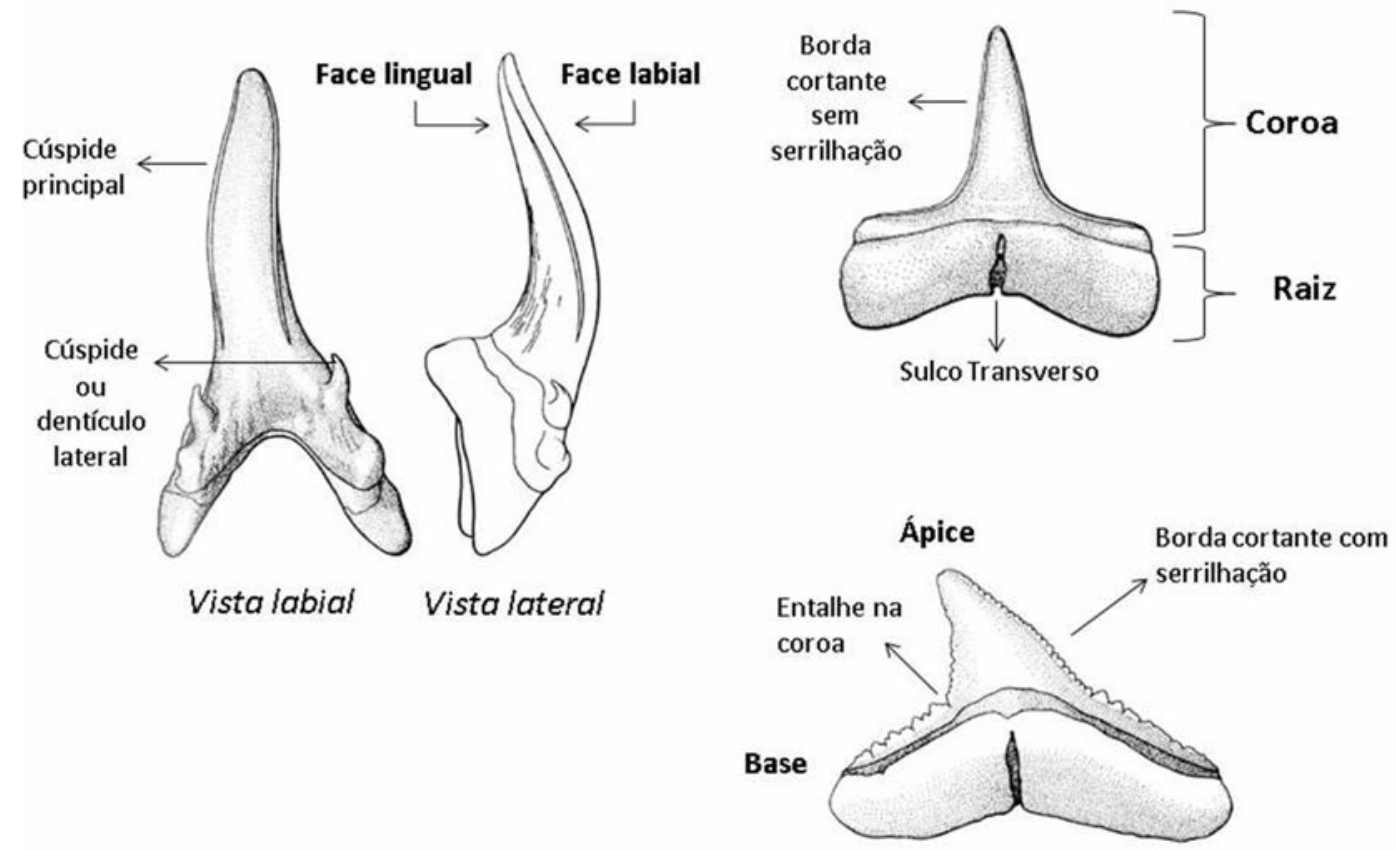

Fig. 1. Dentes de tubarões e principais estruturas diagnósticas. Imagem modificada de Cappetta (2012).

pal elemento diagnóstico (HIGUCHI, 1982; AGUILERA, 2010), através da observação de estruturas como a própria morfologia do otólito, zona opaca, zona hialina e presença do rostro (Figura 2A).

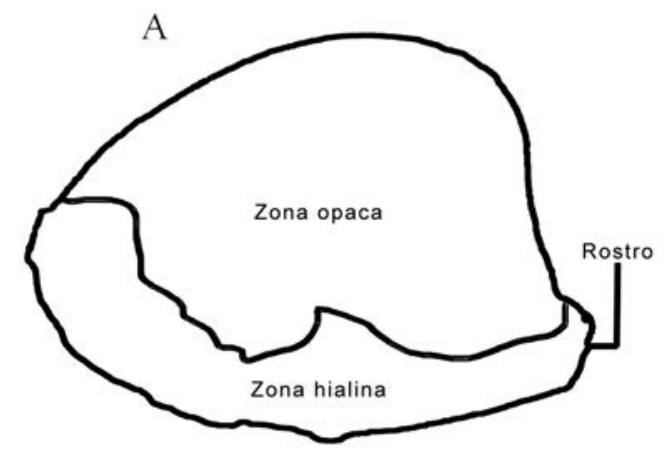

Resultados

Os vestígios de peixes do Sambaqui do Moa

Como ressaltado anteriormente por Kneip et al. (1994) e Silveira (2001) os vestígios de
B

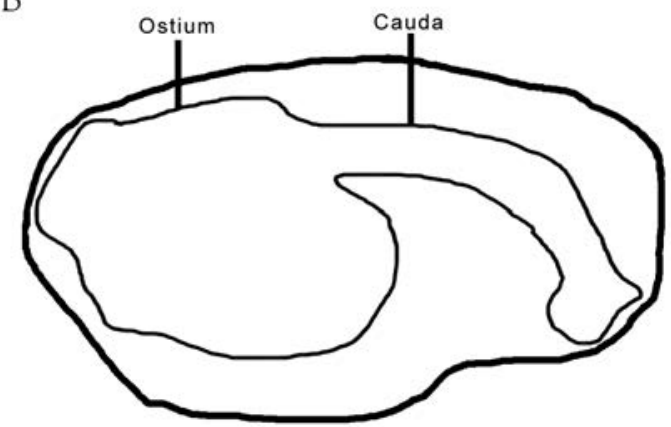

Fig. 2. Otólitos e algumas de suas características diagnósticas para identificação: (A) lapillus (Ariidae) e (B) sagitta (Scianidae). 
peixes são abundantes no Sambaqui do Moa, consequência da utilização destes animais como uma das principais fontes de proteínas utilizadas pelos sambaquieiros. Consequentemente, já existem listas de espécies de peixes, porém o material analisado apresenta novas ocorrências quando comparado com ocorrências já apresentadas anteriormente (Tab. 1).

Neste estudo são apresentadas 9 ocorrências de peixes para o Sambaqui do Moa, sendo 5 inéditas, estas exclusivamente representadas por dentes de tubarões (peixes cartilaginosos). Com relação aos otólitos (peixes ósseos), todos são representantes de espécies já citadas.

\section{Os novos dentes de tubarões do Sambaqui do} Moa

Os tubarões, por se tratarem de peixes cartilaginosos, não apresentam a mesma facilidade de preservação do que outros peixes de constituição exclusivamente óssea, portanto, ficam como vestígios destes animais, apenas suas partes mais mineralizadas, que no caso são: dentículos dérmicos (ou escamas) e dentes. Entretanto, apenas os últimos possibilitam o diagnóstico taxonômico mais preciso (CAPPETTA, 2012).

Nas amostras analisadas foram descritas cinco novas ocorrências de tubarões para o Sambaqui do Moa, são elas: Carcharhinus sp. Galeocerdo cuvier, Sphyrna sp., Carcharias sp., Isurus sp.

\section{Diagnóstico dos tubaróes do Sambaqui do Moa}

Táxon: Carcharhinus sp.

Família: Carcharhinidae

Nome Vulgar: "cação"

Figura: 3A-C

Material: 3 dentes (MPEG-004-006-ZA)

Ocorrência no Sambaqui do Moa: Estrato 1,2 e 3

Diagnose do dente: Dentes em média com $1 \mathrm{~cm}$ de altura, coroa triangular, unicuspidados (uma cúspide) e com borda cortante completamente serrilhada, sendo mais forte na região basal comparativamente as da região apical. A presença de entalhe na base da cúspide central, não foi constante, e quando presente, ocorria em apenas uma das bordas. Em vista lateral apresentam achatamento labiolingual. $\mathrm{Na}$ raiz o sulco transversal nem sempre evidente, possivelmente em decorrência de processos tafonômicos.

Habitat: Comum em ambientes costeiros, usualmente em profundidades de $1-30 \mathrm{~m}$. Podem ocorrer em estuários e uma espécie desse gênero, Carcharhinus leucas, eventualmente invade ambientes de água doce.

Táxon: Galeocerdo cuvier (PERON e LeSUEUR, 1822)

Família: Carcharhinidae

Nome Vulgar: "tubarão-tigre"

Figura: 3D

Material: 1 dente (MPEG-007-ZA)

Ocorrência no Sambaqui do Moa: Estrato 2

Diagnose do Dente: Dente com coroa triangular de base larga (quase o dobro da altura); unicuspidada e fortemente curvada, formando um ângulo obtuso em uma das bordas do dente. Dente fortemente serrilhado, e no caso do material do Sambaqui do Moa, apesar de claramente desgastado, possivelmente por transporte, observa-se em especial na região basal, serrilhações secundárias (serrilhações menores, que só podem ser vistas com auxílio de lupa). A raiz por apresentar-se fragmentada não pode ser descrita em detalhes.

Habitat: Ambientes marinhos e estuarinos. Habitam no mar em um grande intervalo de profundidade, entre 1-371 m, o que significa que podem ocorrer tanto em áreas costeiras quanto no mar adentro.

Táxon: Sphyrna sp.

Família: Sphyrnidae

Nome Vulgar: "tubarão martelo"

Figura: Figura 3E - F

Material: 2 dentes (MPEG-008-009-ZA)

Ocorrência no Sambaqui do Moa: Estratos 2 e 3

Diagnose do dente: Dente de aproximadamente $1 \mathrm{~cm}$ de altura, unicuspidado, apresentando coroa estreita (aguliforme), triangular. 


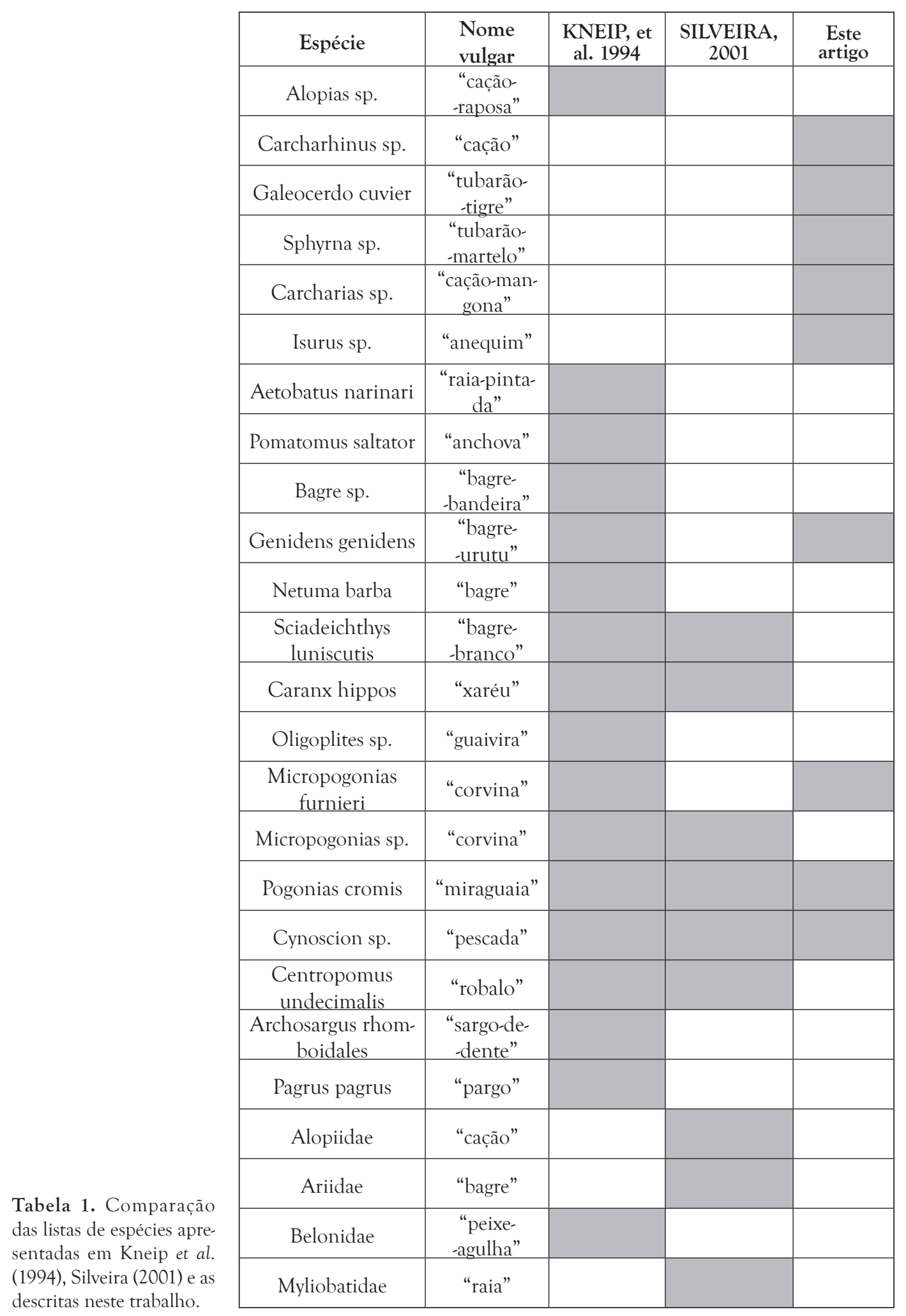


Borda de esmalte lisa ou levemente crenulada em toda sua extensão, sendo mais evidente na região basal. Em vista lateral face lingual achatada ou levemente curvada em direção labial. Raiz com sulco transverso bem marcado e forâmen central aparente.

Habitat: Ambientes marinhos, em intervalo de profundidade entre $8-80 \mathrm{~m}$, ou seja, podem ocorrer em áreas mais próximas à costa. Nesse gênero os filhotes podem adentrar áreas estuarinas (caracterizada pela salinidade intermediária da água, decorrente da influência marinha e continental), pois essas áreas apresentam grande produtividade e são utilizadas como berçários por diversos grupos de peixes.

Táxon: Carcharias sp.

Família: Carcharhinidae

Nome Vulgar: "cação-mangona"

Figura: Figura $3 \mathrm{G}-\mathrm{H}$

Material: 2 dentes (MPEG-010-011-ZA)

Ocorrência no Sambaqui do Moa: Estratos 3 e $1 / 3$

Diagnose do dente: Dentes apresentam mais de $1,5 \mathrm{~cm}$ de altura da coroa, unicuspidados, com borda de esmalte lisa, estreita e alongada, apresentando leves estrias na parte inferior da face labial, em vista lateral a coroa é levemente sigmoide. Não há entalhe entre a cúspide central e a região basal da coroa, porém em cada lado encontra-se um dentículo (ou cúspele) bem desenvolvido e curvado. Assim como na cúspide central, estes também não apresentam crenulações na borda do esmalte. Raiz estreita com laterais fortemente arqueadas.

Habitat: Ambientes marinhos, em geral associados a recifes, portanto relacionados a áreas de profundidade entre $15-25 \mathrm{~m}$, de mares tropicais que apresentem águas claras. Porém, o intervalo de abrangência desse grupo estende-se de 1-191 m, ou seja, o que faz desses representantes grandes caçadores marinhos.

Táxon: Isurus sp.

Família: Lamnidae

Nome Vulgar: "anequim"

Figura: Figura $3 \mathrm{I}$

Material: 1 dente (MPEG-012-ZA)
Ocorrência no Sambaqui do Moa: Estrato 1

Diagnose do dente: Dente de grande proporção com mais de $2,5 \mathrm{~cm}$ de altura, unicuspidado, com coroa longa (altura o dobro da largura), sem serrilhações ou dentículos. Em vista lateral coroa apresenta formato sigmoide, e ausência de entalhe na região basal da coroa. A raiz é robusta, região central desenvolvida e apresenta sulco transverso bem marcado, laterais da raiz são expandidas e arqueadas na região central.

Habitat: Ambientes marinhos, como são considerados animais de grande porte (pertencentes à família do tubarão branco), logo alimentam-se em especial de mamíferos, por esse motivo acabam por se restringir às áreas ocupadas preferencialmente por esses grupos, que seriam profundidades marinhas em torno de 100-150 m, ou seja, raramente ocorrem em áreas mais rasas do litoral; entretanto, é importante lembrar que em Saquarema essas áreas de grande profundidade ocorrem perto da costa, tanto que facilmente são avistadas baleias que utilizam a área como rota migratória.

\section{Os otólitos do Sambaqui do Moa}

Os otólitos são os elementos de peixes ósseos, relacionados ao ouvido interno, que ocorrem dentro da cabeça, em pares. Esses se preservam mais facilmente em sítios arqueológicos por serem partes duras especializadas do sistema acústico-lateral (responsável pelo equilíbrio) dos Actinopterygii, e alguns Sarcopterygii (AGUILERA, 2003). São compostos por carbonato de cálcio, principalmente na forma de aragonita, e matéria orgânica, chamada otolina (AGUILERA, 2004).

Com base nos 39 otólitos presentes nas amostras avaliadas, foram descritos quatro táxons já registrados no Sambaqui do Moa, são eles: Microgoponias furnieri, Pogonias cromis, Cynoscion sp., e Genidens genidens, pertencentes às famílias Scianidae e Ariidae, respectivamente.

Neste artigo as informações registradas anteriormente serão complementadas com dados referentes à diagnose do otólito, bem como o habitat do peixe. 


$$
\begin{aligned}
& \Delta \Delta \\
& 01 \\
& 11 \\
& 11
\end{aligned}
$$


Diagnóstico dos otólitos do Sambaqui do Moa

Táxon: Cynoscion sp.

Família: Scianidae

Nome Vulgar: "pescada"

Figura: Figura 4A-F

Material: 2 otólitos sagitta (MPEG-013-014-ZA)

Ocorrência no Sambaqui do Moa: Estrato 1 e 3 .

Diagnose do otólito: Otólito alongado e suboval, espesso e levemente convexo. Superfície dorsal com nódulos ou tubérculos pouco desenvolvidos. Margem dorsal, ventral e posterior curvadas. Ostium alargado e subcircular, quase fechado anteriormente. Cauda estreita e longa, flexionada ventralmente em arco, no mesmo nível ou acima da margem do ostium. Crista superior e inferior pouco desenvolvidas ou possivelmente erodidas devido ao estado do material.

Habitat: Zonas litorâneas sobre fundos arenosos e lamacentos, próximo a áreas estuarinas.

Táxon: Micropogonias furnieri (DESMAREST, 1823)

Família: Scianidae

Nome Vulgar: "corvina"

Figura: Figura 4G-M

Material: 28 otólitos sagitta (MPEG-015042-ZA)

Ocorrência no Sambaqui do Moa: Estrato 1,2 e 3.

Diagnose do otólito: Otólito em formato sub-romboidal, espesso e convexo. Superfície dorsal apresenta nódulos e tubérculos bem desenvolvidos. Margem dorsal reta; ventral e posterior curvadas. Ostium alargado e subcircular, quase fechado anteriormente. Cauda longa e estreita, apresentando uma expansão arredondada na extremidade; levemente curvada na direção ventral, ponta no mesmo nível ou abaixo da margem do ostium. Crista superior e inferior pouco desenvolvidas ou possivelmente erodidas devido ao estado do material.

Habitat: Zonas litorâneas da plataforma continental, ocorrendo em águas rasas até 60 metros de profundidade.

Táxon: Pogonias cromis (LINNAEUS, 1766) Nome Vulgar: "miraguaia"
Família: Scianidae

Figura: Figura 4N-S

Material: 3 otólitos sagitta (MPEG-043045-ZA)

Ocorrência no Sambaqui do Moa: Estratos 1,2 e 3.

Diagnose do otólito: Otólito sub-retangular, com a margem dorsal levemente curvada para o centro, muito espesso, convexo. Margem ventral e posterior curvadas. Superfície dorsal sem nódulos ou tubérculos. Ostium alargado e subcircular quase fechado anteriormente. Cauda curta e larga, levemente curvada na direção ventral, no mesmo nível ou acima da margem do ostium. Crista superior e inferior pouco desenvolvida ou possivelmente erodidas devido ao estado do material.

Habitat: Vive em águas litorâneas, normalmente em fundos arenosos e lamacentos, principalmente com grandes escoamentos fluviais. Juvenis também podem habitar estuários.

Táxon: Genidens genidens (CUVIER, 1829)

Nome Vulgar: "bagre-urutu"

Família: Ariidae

Figura: Figura 5

Material: 6 otólitos lapillus (MPEG-046051-ZA)

Ocorrência no Sambaqui do Moa: Estrato 1,2 e 3.

Diagnose do otólito: Otólito em forma subcircular, espesso e biconvexo, com margens lisas. As superfícies dorsal e ventral estão erodidas na maior parte do espécime, dificultando a observação de alguns caracteres (zona opaca e hialina em vista ventral; e nas linhas de crescimento na vista dorsal). $\mathrm{O}$ umbo encontra-se proeminente na vista dorsal, porém bastante desgastado para sua observação. Pode-se verificar o rostro na margem anterior, no entanto, possivelmente por processos tafonômicos não está presente em todos os espécimes.

Habitat: Habitam águas marinhas litorâneas até 50 metros de profundidade. Frequentam também áreas estuarinas e lagunas altamente salinas. 

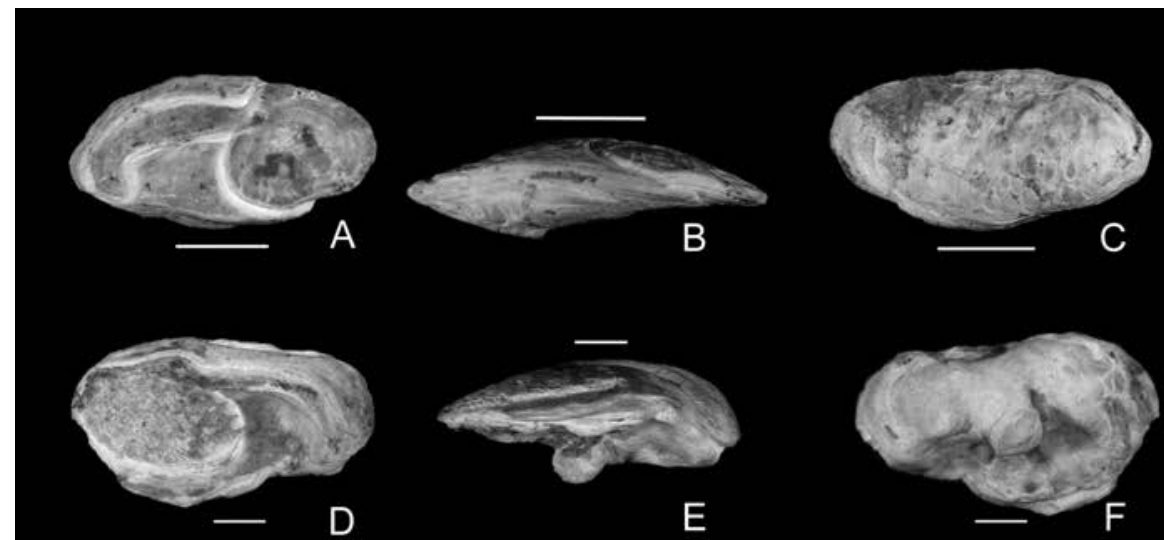

E
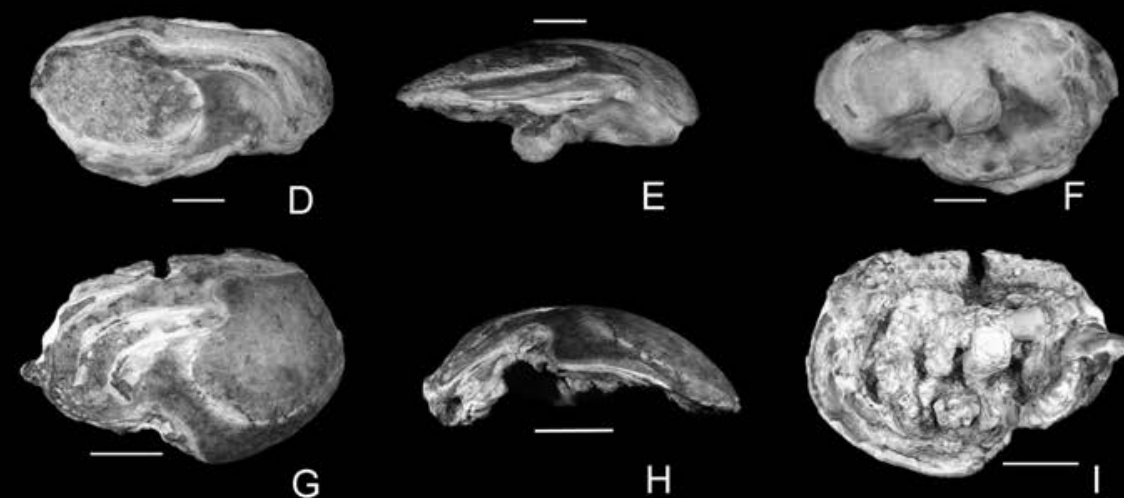

$\mathrm{H}$
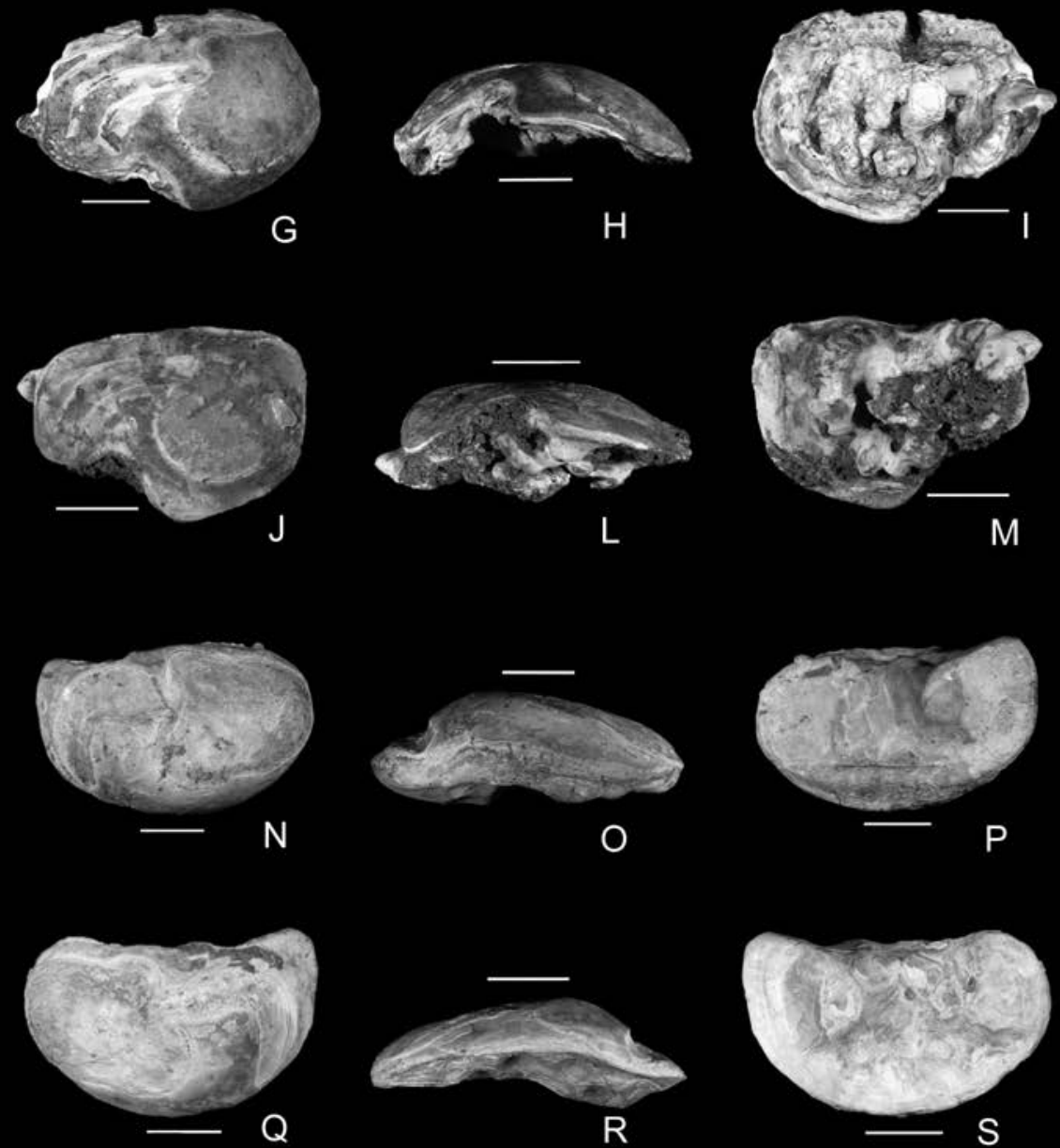

Fig. 4. Otólitos de Scianidae identificados do Sambaqui do Moa. Coluna à esquerda em vista ventral; ao centro em vista lateral; e à direita em vista dorsal. (A, B, C, D, E e F) Cynoscion sp.; (G, H, I, J, L e M) Micropogonias furnieri; (N, O, P, Q, R e S) Pogonias cromis. Escala: $5 \mathrm{~mm}$. 

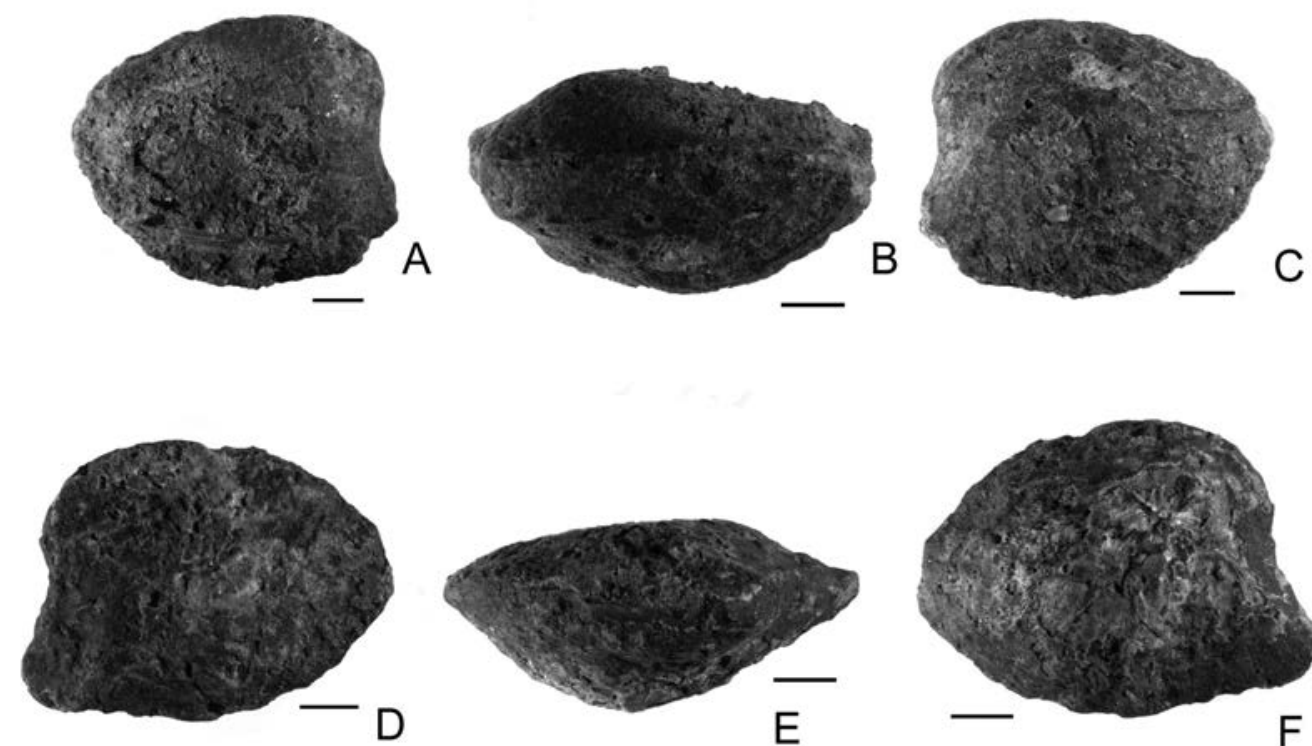

E

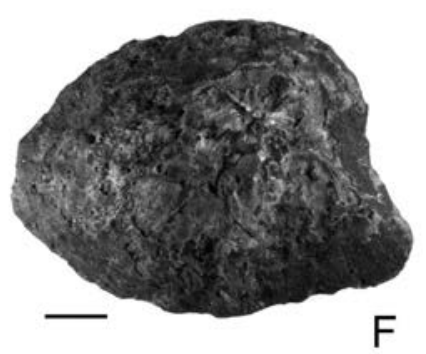

Fig. 5. Otólitos de Ariidae (Genidens genidens) identificados do Sambaqui do Moa. Coluna à esquerda em vista ventral; ao centro em vista lateral; e à direita em vista dorsal. Escala: $2 \mathrm{~mm}$.

Os habitantes do Sambaqui do Moa e os vestígios de peixes

Corroborando com os dados já apresentados por Silveira (2001), as ocorrências registradas neste trabalho demonstram a ocorrência de peixes também pertencentes a uma fauna costeira, ou seja, preferencialmente marinhos que habitam profundidades moderadas, como, por exemplo, os gêneros de tubarões, os quais possuem representantes atuais habitando em diferentes intervalos de profundidade, ou seja, em áreas mais rasas e/ou mais profundas (COMPAGNO, 1984).

Porém, a diversidade de ambientes utilizados por esses peixes não limita-se apenas à profundidade, mas também à salinidade, visto que a maior parte das espécies transitam por estuários - ambiente caracterizado por apresentar influência tanto de água doce quanto marinha. As espécies Genidens genidens, Micropogonias furnieri, Pogonias cromis e os gêneros de tubarões
Carcharhinus, Galeocerdo e Sphyrna são exemplos desse caráter dinâmico da fauna, pois transitam facilmente em ambientes marinhos e estuarinos (COMPAGNO, 1984; ACERO \& BETANCUR, 2007; FROESE \& PAULY, 2012).

Essa fauna especializada em grandes variações é o reflexo do ambiente em torno do Sambaqui do Moa, que assumindo uma tendência comum no litoral brasileiro, está situado em área costeira transicional, caracterizada pela diversidade de ambientes (DeBLASIS et al., 2007), o que consequentemente gera uma alta diversidade de recursos a ser explorados pelos grupos sambaquieiros (KNEIP, 1999).

Essa heterogeneidade de ambientes, provavelmente impulsionou o desenvolvimento de diversas estratégias de pesca, a atividade predominante para captação de recursos, empregada pelos grupos que ali habitaram, assim como em outros sambaquis da região litorânea brasileira (KNEIP et al., 1997, FIGUTI, 1994/5).

Como afirma Silveira (2001: 93), a partir da análise do ambiente de entorno do Sambaqui 
do Moa, os grupos provavelmente conheciam diversas modalidades de pesca, confirmadas pela presença de pontas de arpões feitas com ossos de mamíferos, anzóis de concha e agulhas de ossos de peixe (esporões), essas possivelmente, utilizadas para a confecção de redes de pesca ou mesmo de espinhéis.

As espécies de peixes aqui apresentadas podem ser facilmente pescadas com a ajuda de redes e espinhéis, ou mesmo com a técnica de curral. Já os tubarões necessitam de estratégias mais elaboradas, seja com o auxilio de embarcações, seja através de estratégias de captura quando o animal encalhou por se aproximar de áreas mais rasas, principalmente em estuários (FRANCO, 1992 apud GONZALEZ, 2005). Apesar de nas escavações do Sambaqui do Moa não ocorrer evidências de embarcações, há outros indícios (evidências indiretas) que sustentam a presença destes (KNEIP, 1994; SILVEIRA, 2001).

Essa relação da pesca de tubarões por aproximação da costa, o suficiente para que ocorra o encalhe do animal, é bem forte para os representantes do gênero Isurus, considerados tubarões velozes e de grande porte (REIF, 1985). Isso pode ser confirmado pela proporção do seu dente em comparação com os outros encontrados (Figura 1). Portanto, não são pescados facilmente com redes, mas podem ser capturados com arpões. Algumas evidências denotam a presença de pontas de arpão no Sambaqui do Moa, e tanto a utilização do arpão quanto a própria geografia local podem sustentar a utilização desta técnica de pesca para a captura desses animais.

Do sambaqui do Moa é possivel chegar facilmente a um conjunto de pedras próximas à costa, que, por sua vez, neste ponto, tem a plataforma (área plana) muito curta, chegando a poucos metros do talude (área inclinada de grande profundidade do mar), tanto que, graças a essa característica, ainda hoje é possível observar "próximo à beira da praia" baleias que utilizam esta área como rota migratória. Portanto, estar em um ponto alto, muito próximo da área onde esses tubarões circulam (principalmente em função dos mamíferos marinhos, seu principal alimento) é um facilitador para a pesca desses animais com arpões.
Ainda com relação aos tubarões, foram observados dentes trabalhados (com perfurações na raiz e alisamento da base), pertencentes aos gêneros Carcharhinus e Galeocerdo, esse último evidente mesmo em decorrência do estado fragmentário do dente. As modificações foram perfurações únicas e centrais na raiz (ou base de fixação), provavelmente com o objetivo da utilização desses como adorno (pingentes, colares, entre outros) ou até mesmo como componente de algum instrumento utilizado para caça ou pesca (GUIDON \& PALESTRINI, 1962; GONZALEZ, 2005).

\section{Conclusão}

Os registros de peixes aqui apresentados para o Sambaqui do Moa são resultado da identificação de dentes e otólitos. Os dentes pertencem aos tubarões dos gêneros Carcharinus, Galeocerdo, Sphyrna, Carcharias, Isurus. Os otólitos pertencem aos peixes ósseos Cynoscion sp., Micropogonias furnieri, Pogonias cromis e Genidens genidens. Essa fauna é representativa de uma grande variabilidade de ambientes, tais como áreas de diferentes profundidades do mar (praia e oceano), lagunas e estuários, sendo os dois últimos elementos que reforçam o ambiente costeiro transicional, já descrito para o sambaqui (p.e. KNEIP, 1999; SILVEIRA, 2001). O acréscimo de novos táxons à lista de espécies já documentadas para o sambaqui se deve em especial aos gêneros de tubarões supracitados, os quais foram identificados exclusivamente pelos seus dentes. Esses, em alguns casos, apresentaram modificações, como perfurações e/ou alisamentos da raiz, realizadas pelos povos sambaquieiros, visando, provavelmente, à confecção de adornos ou ferramentas. A diversidade de peixes aqui encontrada indica a utilização de diversas técnicas de captura empregando diferentes instrumentos para a pesca, tais como anzóis, redes e espinhéis. Além disso, esses testemunhos da fauna são evidências do conhecimento e da exploração dos diferentes ambientes pelos povos sambaquieiros. 


\section{Agradecimentos}

Os autores agradecem ao Dr. Orangel Aguilera pelo auxílio nas identificações dos espécimes, a Carolina Andrade pelo tratamento das imagens, a John Fletcher pela revisão do abstract e ao referee anônimo pelas preciosas observações no manuscrito.

COSTA, S.A.R.F.; LUZ, Z.A.S.; SILVEIRA, M.I.; SANTOS, H.M.M. Contributions to Moa's Shellmound Zooarchaeology: New ichthyologic remains. R. Museu Arq. Etn., São Paulo, n. 22: 51-65, 2012.

Abstract : This paper presents the description and a brief discussion on the ichthyologic remains recovered from excavations in Moa's Shellmound, located in Saquarema/RJ. There are 39 otoliths belonging to the taxa: Cynoscion sp., Micropogonias furnieri, Pogonias cromis and Genidens genidens, and 9 shark teeth of the genus Carcharhinus, Galeocerdo, Sphyrna, Carcharias and Isurus, these unprecedent even for the located area. And from these recordings, it was possible to verify paleoenvironment considerations, and the use of these fishes within the culture of the shellmound populations.

Keywords: Zooarchaeology, Moa’s Shellmound, Fishes.

\section{Referências bibliográficas}

ACERO, A. F. \& BETANCUR-R, R.

2007 Monophyly, affinities, and subfamilial clades of sea catfishes (Siluriformes: Ariidae). Ichthyol. Explor. Freshwaters, vol. 18, no. 2. 133-143.

AGUILERA, O. \& AGUILERA, D. R.

2003 Two New Otolith-Based Sciaenid Species of the Genus Plagioscion from South American Neogene Marine Sediments. Journal of Paleontology, v. 77, no. 6. 1133-1138.

AGUILERA, O. \& AGUILERA, D. R.

2004 New Miocene Otolith-Based Sciaenid Species (Pisces, Perciformes) from Venezuela. Special Papers in Paleontology, 71. 49-59.

AGUILERA, O.

2010 Peces Fosiles del Caribe de Venezuela. GeoBio Consultores C.A., Venezuela. 255 p.

BANDEIRA, A. M.

2007 O povoamento da América visto a partir dos sambaquis do Litoral Equatorial Amazônico do Brasil. FUMDHAMentos, v. 7, 430-468.
CAPPETTA, $\mathrm{H}$.

2012 Handbook of Paleoichthyology v. 3E. Ed. Semper Bonis Artbus, 512 p.

CASTILHO, P. V.; SIMÕES-LOPES, P. C.

2001 Zooarqueologia dos mamíferos aquáticos e semiaquáticos da Ilha de Santa Catarina, sul do Brasil. Revista brasileira de Zoologia. v. $18(3): 719-727$.

COMPAGNO, L. J. V.

1984 FAO Species Catalogue. Vol. 4. Sharks of the world. An annotated and illustrated catalogue of shark species known to date. Part I - Hexanchiformes to Lamniformes. FAO Fish. Synop. 125(4/1): 1-249.

COMPAGNO, L. J. V.

1984 FAO Species Catalogue. Vol. 4. Sharks of the world. An annotated and illustrated catalogue of shark species known to date. Part II - Carcharhiniformes. FAO Fish. Synop. 125(4/2): 1-655. 
DEBLASIS, P.; KNEIP, A.; SCHEEL-YBERT, R.; GIANNINI, P. C.; GASPAR, M. D.

2007 Sambaquis e Paisagem, Dinâmica natural e arqueologia regional no litoral sul do Brasil. Arqueologia Sul-americana. v. 3 (1): 29-61.

EVANS, J. G.

1972 Land snails in archaeology with special reference to the British Isles. Journal of Archaeology Science. vol. 1. 113 p.

FIGUTI, L.

1994/95 Os sambaquis Cosipa (4200 a 1200 anos

BP): Estudo da subsistência dos povos pescadores coletores pré-históricos da Baixada Santista. In: Revista de Arqueologia, São Paulo, 8(2):267-283.

FRANCISCO, B. H. R.

1999 O Homem e a Geo-História da Região de Saquarema. Rio de Janeiro, 1999. 277 f. Tese (Doutorado) - Instituto de Geociências, Universidade Federal do Rio de Janeiro.

FROESE, R. \& D. PAULY.

2012 FishBase. World Wide Web electronic publication. www.fishbase.org, version (04/2012).

GONZALEZ, M. M. B. \& AMENOMORI, S. N.

2003 Osteologia e Utilização de Dentes de Tubarão-branco, Carcharodon carcharias (Linnaeus, 1758) (Elasmobranchii, Lamnidae) em Sambaquis do Estado de São Paulo. Revista do Museu de Arqueologia e Etnologia da Universidade de São Paulo, 13: 25-37.

GONZALEZ, M. M. B.

2005 Use of Pristis spp. (Elasmobranchii: Pristidae) by Hunter-Gatherers on the Coast of São Paulo, Brazil. Neotropical Ichthyology, 3(3):421-426.

GUIDON, N. \& PALLESTRINI, L.

1962 Estudo da indústria do sambaqui do Mar Casado. Anhembi 47: 49-60.

GUIMARÃES, M. S. B. C.

2003 Do Lixo ao Luxo: As premissas teórico-metodológicas e a noção de sambaqui. Boletim do Museu Nacional, Nova Série, Antropologia. Rio de Janeiro, n. 63, p. 1-23.

HIGUCHI, H.

1982 Estudo Osteológico de Bagres Marinhos do Litoral Sul do Brasil (Osteichthyes; Siluroidei, Ariidae). São Paulo, 1982. 135 f. Dissertação (Mestrado) - Instituto de Biociências, Universidade de São Paulo.

KNEIP, L.M.; CRANCIO, F.; FRANCISCO, B. H. R. 1988 O Sambaqui da Beirada (Saquarema, $\mathrm{RJ}$ ): aspectos culturais e paleoambientais. Revista de Arqueologia 5(1): 41-54.
KNEIP, L.M. ; PALESTRINI, L.; CRANCIO, F.; MACHADO, L. C.

1991 As estruturas e suas inter-relações em sítios de pescadores-coletores pré-históricos do litoral de Saquarema, RJ. Boletim Série Ensaios $n^{\circ}$ 05. Instituto de Arqueologia Brasileira. Rio de Janeiro- RJ.

KNEIP, L.M.

1994 Cultura material e subsistência das populações pré-históricas de Saquarema, RJ. Documento de Trabalho 2, Sér. Arqueol., Museu Nacional, Univ. Red. Rio de Janeiro: $1-120$.

KNEIP, L M..; CRANCIO, F.; SANTOS, C. M. C.; MAGALHÃES, R. M. M.; MELLO, E. M. B.

1997 O sambaqui do Saco e de Madressilva Saquarema, RJ. Documento de Trabalho. Série Arqueologia, Museu Nacional, UFRJ, Rio de Janeiro, No 4, 67 p.

KNEIP, L. M.

1999 Pré-história de Saquarema, RJ. In MC Tenó-rio, Pré-história de Terra Brasilis. UFRJ - RJ. 223 - 232.

LAM, Y. M.; PEARSON, O. M.; MAREAN, C. W.; CHEN, $\mathrm{X}$.

2003 Bone density studies in zooarchaeology. Journal of Archaeological Science. v. 30: 1701-1708.

LEROI-GOURHAN, A. \& BREZILLION, M.

1972 Fouilles de Pincevent. Essai d' analyses ethnographique d'un habitat magdalénien. Suplément à Gallia Préhistoire, 7, Paris, 32p.

MACHADO, S. M.; LUZ, Z. A. S.; SILVA, J. F. B. R.; SILVEIRA, M. I.; COSTA, S. A. R. F.

2011 Contributions to Moa's Shellmound: fish microfossils analysis. Brazilian Geographical Journal: Geosciences and Humanities research medium, Uberlândia, v. 2, n. 1, p. 56-68.

PURDY, R. W.

2006 A Key do Common Genera of Neogene Shark Teeth. Disponivel em: http://www.paleobiology.si.edu/pdfs/sharktoothKey.pdf. Acesso em: 28/05/2012.

REIF, W. E.

1985 Squamation and Ecology of Sharks. Courier Forschungsinstitut Senckenberg 78: 1-255.

SCHEEL-YBERT, R.

2003 Relações dos Habitantes de Sambaquis com o Meio Ambiente: Evidências de Manejo de Vegetais na Costa Sul-Sudeste do Brasil durante o Holoceno Superior. In: Resumos expandidos, IX Congresso da Associação Brasileira de Estudos do Quaternário. Disponível em: http://www.arqueologia. 
mn.ufrj.br/docs/papers/rita/ABE-

QUA2003.pdf, Acesso em: 22/05/10.

SCHEEL-YBERT, R.; AFONSO, M. C.; BARBOSA-GUIMARÃES, M.; GASPAR, M. D.; YBERT, J-P.

2009 Considerações sobre o papel dos sambaquis como indicadores do nível do mar. Quaternary and Environmental Geosciences. 01(1): 3-9.

\section{SILVEIRA, M. I.}

2001 Você é o que você come. Aspectos da subsistência no Sambaqui do Moa Saquarema/ RJ. São Paulo, 2001. 165 f. Tese (Doutorado) - Faculdade de Filosofia, Letras e Ciências Humanas, Universidade de São Paulo. 